\title{
AVALIAÇÃO DA QUALIDADE DE VIDA DE PACIENTES SUBMETIDOS AO TRANSPLANTE DE CÉLULAS-TRONCO HEMATOPOÉTICAS
}

\section{EVALUATION OF QUALITY OF LIFE OF PATIENTS SUBMITTED TO HEMATOPOETIC STEM CELL TRANSPLANTATION}

\author{
Marciele Braga', Andreza Lima Cardoso², Bruna Schioํ, Francine Ziegler Leal ${ }^{4}$ \\ Jenifer Mielke ${ }^{5}$, Juliana de Oliveira Mozzaquatro', Rosmari Horner ${ }^{7}$
}

\section{RESUMO}

O objetivo do presente trabalho foi avaliar a qualidade de vida (QV) dos pacientes pós transplante de células tronco hematopoéticas (TCTH) autólogo e alogênico. Trata-se de um estudo descritivo, exploratório com abordagem quali-quantitativa, realizado nos meses de março a dezembro de 2016 - em um Hospital Universitário. Fizeram parte da pesquisa 21 pacientes adultos pós-TCTH, que seguiam acompanhamento no referido hospital, sendo utilizada a escala de avaliação funcional da terapia do câncer - transplante de medula óssea (Functional Assessment of Cancer Therapy - Bone Marrow Transplantation - FACT-BMT) e para análise dos dados, o programa Statistical Package for Social Sciences (SPSS), versão 15.0. Os resultados obtidos neste estudo permitem ratificar, comparando com avaliações nacionais e internacionais, o impacto positivo do TCTH em relação à qualidade de vida geral dos pacientes submetidos a este tratamento, apesar de algumas funções apresentarem-se mais comprometidas. Estudos que identificam a influência dos efeitos do TCTH na QV dos pacientes submetidos a esse procedimento são escassos. Conhecer o impacto do TCTH na vida do transplantado auxilia a equipe multidisciplinar a desenvolver um plano de assistência integral com estratégias para diminuir os efeitos colaterais desse procedimento e melhorar a qualidade de vida do paciente em todos os momentos do tratamento.

Descritores: Transplante de Medula Óssea; Qualidade de Vida; Internato não Médico.

\footnotetext{
ABSTRACT

The objective of the present study was to evaluate the quality of life of individuals after autologous and allogenic HSCT. This is a descriptive, exploratory study with a qualitative-quantitative approach. Data were collected between March and December 2016, and the Functional Assessment of Cancer Therapy (FACT-BMT) was used for the Functional Assessment of Bone Marrow Transplantation (FACT-BMT). The statistical procedure of data analysis was done through the statistical package SPSS (Statistical Package for Social Sciences), version 15.0. The results presented in this study allowed us to visualize the positive impact of HSCT on the general quality of life of patients undergoing this treatment, although some functions were more compromised. Studies of this nature, which identify the influence of the effects of HSCT on the QOL of the patients submitted to this procedure are scarce. Knowing the impact of TCTH on the life of the transplant helps the multidisciplinary team to develop a comprehensive care plan with strategies to reduce the side effects of this procedure and improve the quality of life of the patient at all times of treatment.
}

${ }^{1}$ Graduada em Enfermagem pela Universidade Regional Integrada (URI), Santo Angelo, RS, Brasil.

${ }^{2}$ Graduada em Enfermagem pela Universidade Federal de Santa Maria (UFSM), Santa Maria, RS, Brasil.

${ }^{3}$ Graduada em Fonoaudiologia pela Universidade Federal de Santa Maria (UFSM), Santa Maria, RS, Brasil.

${ }^{4}$ Graduada em Serviço Social pelo Centro Universitário Franciscano (UNIFRA), Santa Maria, RS, Brasil.

${ }^{5}$ Graduada em Odontologia pela Universidade Federal de Santa Maria (UFSM), Santa Maria, RS, Brasil.

${ }^{6}$ Graduada em Farmácia pela Universidade Federal de Santa Maria (UFSM), Santa Maria, RS, Brasil.

${ }^{7}$ Doutora em Química pela Universidade Federal de Santa Catarina (UFSC), Florianópolis, SC, Brasil. 


\section{Introdução}

O transplante de medula óssea (TMO) ou transplante de células tronco hematopoéticas (TCTH) é uma terapêutica utilizada principalmente para doenças hematológicas, mas também - para doenças hereditárias, imunológicas e oncológicas ${ }^{1}$. A técnica consiste na utilização de altas doses de quimioterapia e/ou radioterapia e a posterior infusão de células de um doador ou do próprio receptor, com a finalidade de substituir a medula comprometida e restabelecer a hematopoese sem a presença de células anômalas".

O processo de TCTH envolve - a seleção do indivíduo, receptor e doador, e o tipo de transplante indicado, dentre eles, TMO autólogo, alogênico, haploidêntico ou singênico, este último em desuso pelo alto índice de recidivas ${ }^{2}$. As etapas que constituem o TCTH são o pré-transplante, onde são resolvidas as questões burocráticas e realizado os exames necessários para conhecimento da condição clínica do(s) indivíduo(s); o TCTH em si, caracterizado pela hospitalização e os procedimentos de condicionamento e posterior infusão da medula coletada até a alta hospitalar; e o pós-TCTH, imediato e tardio ${ }^{3}$.

As complicações do pós-TCTH imediato são decorrentes principalmente do condicionamento e do posterior período de aplasia medular, trazendo diversas complicações físicas e emocionais, associadas também ao isolamento social necessário durante o período de hospitalização ${ }^{4}$. 0 problema mais temido após a infusão da nova medula é a doença do enxerto contra o hospedeiro (DECH), que consiste na manifestação imunológica das células do doador contra as células do receptor, desencadeando diversas complicações clínicas graves, tornando esse o momento mais crítico do transplante e com o maior risco de óbito ${ }^{5}$. Somado a todo esse processo de tratamento, aparecem às angústias e sofrimentos, que os acompanham desde o diagnóstico da doença, tratamentos anteriores, expectativas e frustrações vividas que se refletem em todas as etapas do processo de transplante.

Apesar da alta complexidade do TCTH, este tem se tornado um procedimento cada vez mais utilizado ao longo dos anos por ser uma possibilidade de cura após tentativas com tratamento convencional. Segundo a Associação Brasileira de Transplante de órgãos ${ }^{6}($ ABTO), no Brasil somente durante o primeiro semestre de 2016 foram realizados 976 TCTH, dentre os quais 626 do tipo autólogo e 350 do tipo alogênico. Mesmo com o sucesso do transplante, existem consequências que interferem em aspectos psicossociais, cognitivos e orgânicos do paciente, refletindo na sua qualidade de vida $(\mathrm{QV})$ posteriormente ao transplante.

Atualmente a QV é um tema muito utilizado em pesquisas científicas. Conceitualmente, ainda não há um consenso sobre sua definição, mas vários especialistas junto à Organização Mundial de Saúde (OMS) a descrevem de maneira geral como "a percepção do indivíduo de sua posição na vida no contexto da cultura e sistema de valores nos quais ele vive em relação aos seus objetivos, expectativas, padrões e preocupações"7. Observa-se que a definição de QV é subjetiva, dinâmica, onde vários aspectos podem ser levados em consideração, resultando para cada indivíduo/ população uma opinião singular sobre sua definição. Entretanto, atualmente, além da QV dita de conhecimento popular, vem sendo muito utilizada na área científica a Qualidade de Vida Relacionada à Saúde (QVRS), em que informações subjetivas relacionadas às doenças podem ser mensuradas/quantificadas ${ }^{8}$.

$\mathrm{Na}$ área da hematologia-oncologia, desde o diagnóstico e principalmente durante o tratamento, os indivíduos são submetidos a procedimentos e terapias potencialmente agressivas, e o TCTH é substancialmente uma delas, podendo trazer implicações negativas na QV dos transplantados.

Indivíduos submetidos ao TCTH experienciam múltiplos sintomas, causados pela doença como também pelo próprio tratamento, que podem afetar de forma negativa a QVRS. Estudos que avaliem a QV de pacientes submetidos a essa terapêutica servem para avaliar as consequências do TCTH, auxiliar na tomada de decisão sobre o transplante, tanto para a equipe quanto para o paciente.

Com o aumento da utilização do TCTH devido ao aprimoramento e evolução na sua técnica, houve respectivamente o aumento da expectativa de vida. Com isso, a QV pós-TCTH passou a ser uma questão ainda mais importante, tornando necessária a revisão das práticas de assistência a estes indivíduos e família?

O objetivo do presente estudo foi avaliar a qualidade de vida de indivíduos adultos pós-TCTH autólogo e alogênico admitidos em um Hospital Universitário no período compreendido entre março a dezembro de 2016. 


\section{Metodologia}

Trata-se de um estudo descritivo, exploratório com abordagem quali-quantitativa, sobre a QV de paciente submetidos ao TCTH autólogo e alogênico em um Hospital Universitário do interior do Rio Grande do Sul. Participaram dessa análise 21 pacientes adultos do período pós-TCTH, escolhidos aleatoriamente, e que não representaram o número total dos pacientes internados no período estudado, os quais seguem em acompanhamento no ambulatório pós-TCTH. O período das coletas foi entre os meses de março a dezembro de 2016.

Foram convidados os indivíduos que correspondiam aos critérios de inclusão: ter sido submetido a TCTH autólogo ou alogênico independente do período pós transplante; idade superior a 18 anos; concordar em participar voluntariamente do estudo após exposição dos objetivos/esclarecimento de dúvidas e assinatura do termo de consentimento.

Dos 21 pacientes entrevistados, 52,4\% (11) eram portadores de mieloma múltiplo (MM); 14,3\% (3) de leucemia mielóide aguda (LMA) e o restante distribuídos entre leucemia mielóide crônica, linfoma de Hodgkin, linfoma não-Hodgkin e mielofibrose. A idade mínima foi de 39 anos e a máxima 70. Destes pacientes, 15 (71,4\%) realizaram transplante autólogo e $6(28,6 \%)$ alogênico.

Para a coleta dos dados foi utilizado a Escala de Avaliação Funcional da Terapia do Câncer - Transplante de Medula Óssea (Functional Assessment of Cancer Therapy - Bone Marrow Transplantation - FACT-BMT), validado e traduzido para a língua portuguesa. Segundo Mastropietro et al. ${ }^{10}$ este instrumento foi traduzido e validado com sucesso, e por sua simplicidade de aplicação, torna-se um método prático para pesquisas clínicas no Brasil.

A FACT-BMT na sua terceira versão é composta por 47 questões distribuídas em seis domínios: bem-estar físico, bem-estar social/familiar, relacionamento com o médico, bem-estar emocional, bem-estar funcional e preocupações adicionais ${ }^{3}$. Esta escala é específica para pacientes com câncer que realizaram TCTH, sendo um instrumento que pode ser autoaplicável ou lido pelo entrevistador, dependendo do nível de escolaridade e condições do indivíduo.

A coleta foi realizada na forma de entrevista individual antes ou após a consulta ambulatorial dos indivíduos, com tempo médio de duração de 20 minutos. Na aplicação era explicado que haveria diversas afirmações com parâmetro de resposta entre 0 (nenhum/pouco) a 4 (muito), sendo que quanto maior a concordância com a questão maior seria 0 escore.

O procedimento estatístico de análise dos dados foi feita através do pacote estatístico SPSS (Statistical Package for Social Sciences), versão 15.0. Primeiramente foi realizada a estatística descritiva dentro dos domínios da escala (bemestar físico, social/familiar, relacionamento com o médico, bem-estar emocional, funcional e preocupações adicionais). Posteriormente foi analisada a fidedignidade por meio do alfa de Cronbach, que segundo Formiga ${ }^{11}$ "é um dos indicadores psicométricos mais utilizados para verificar a fidedignidade e validade interna do instrumento, o qual deverá apresentar um alfa igual a 1. Desta maneira, quanto mais próximo estiver desse número, melhor será sua precisão".

O presente trabalho faz parte do projeto "O Papel de uma Equipe Multidisciplinar na Integralidade da Atenção ao Paciente Oncológico" aprovado pelo Comitê de Ética em Pesquisa com Seres Humanos da Universidade Federal de Santa Maria (UFSM) sob o número CAAE 10291913.3.0000.5346, atendendo as prerrogativas da Resolução n $466 / 12$ do Conselho Nacional de Saúde.

\section{Resultados e Discussão}

\section{Bem-estar físico}

De acordo com os dados que podem ser visualizados na Tabela 1, a maioria dos indivíduos não se sente mais doente $(57,1 \%)$, e os efeitos colaterais do tratamento atualmente não os têm incomodado (35\%). Apesar de não haver um comprometimento significativo, a dor ainda está presente em suas vidas, sendo que $(33,4 \%)$ a descrevem como "mais ou menos" presente, e $(23,8 \%)$ "muito" presente. 
Tabela 1 - Avaliação das questões referentes ao bem- estar físico

\begin{tabular}{c|c|c|c|c|c}
\hline $\begin{array}{c}\text { BEM-ESTAR Físıco } \\
\text { (n=21) }\end{array}$ & $\begin{array}{c}\text { Nem um } \\
\text { pouco }\end{array}$ & $\begin{array}{c}\text { Um } \\
\text { pouco }\end{array}$ & $\begin{array}{c}\text { Mais ou } \\
\text { menos }\end{array}$ & Bastante & Muito \\
\hline 1- Estou sem energia & $\begin{array}{c}6 \\
(28,6 \%)\end{array}$ & $\begin{array}{c}4 \\
(19,0 \%)\end{array}$ & $\begin{array}{c}4 \\
(19,0 \%)\end{array}$ & $\begin{array}{c}6 \\
(28,6 \%)\end{array}$ & $\begin{array}{c}1 \\
(4,8 \%)\end{array}$ \\
\hline 2 - Fico enjoado(a) & $\begin{array}{c}14 \\
(66,6 \%)\end{array}$ & $\begin{array}{c}1 \\
(4,8 \%)\end{array}$ & $\begin{array}{c}1 \\
(4,8 \%)\end{array}$ & $\begin{array}{c}2 \\
(9,5 \%)\end{array}$ & $\begin{array}{c}3 \\
(14,3 \%)\end{array}$ \\
\hline $\begin{array}{c}\text { 3 - Por causa da minha condição } \\
\text { física, tenho dificuldade em } \\
\text { atender às necessidades } \\
\text { de minha família }\end{array}$ & $\begin{array}{c}9 \\
(45,0 \%)\end{array}$ & $\begin{array}{c}1 \\
(5,0 \%)\end{array}$ & $\begin{array}{c}1 \\
(5,0 \%)\end{array}$ & $\begin{array}{c}2 \\
(10,0 \%)\end{array}$ & $\begin{array}{c}7 \\
(35,0 \%)\end{array}$ \\
\hline 4 - Tenho dores & $\begin{array}{c}4 \\
(19,0 \%)\end{array}$ & $\begin{array}{c}2 \\
(9,5 \%)\end{array}$ & $\begin{array}{c}7,0 \\
(33,4 \%)\end{array}$ & $\begin{array}{c}3 \\
(14,3 \%)\end{array}$ & $\begin{array}{c}5 \\
(23,8 \%)\end{array}$ \\
\hline $\begin{array}{c}7 \\
\text { tratamento me incomodam }\end{array}$ & $\begin{array}{c}3 \\
(35,0 \%)\end{array}$ & $\begin{array}{c}2 \\
(15,0 \%)\end{array}$ & $\begin{array}{c}5 \\
(10,0)\end{array}$ & $\begin{array}{c}5 \\
(25,0 \%)\end{array}$ & $\begin{array}{c}3 \\
(15,0 \%)\end{array}$ \\
\hline $\begin{array}{c}12 \\
\text { - Sinto-me doente }\end{array}$ & $\begin{array}{c}2 \\
(57,1 \%)\end{array}$ & $\begin{array}{c}1 \\
(9,5 \%)\end{array}$ & $\begin{array}{c}3 \\
(4,8 \%)\end{array}$ & $\begin{array}{c}3 \\
(14,3 \%)\end{array}$ & $(14,3 \%)$ \\
\hline 7 - Tenho que me deitar \\
durante o dia & $\begin{array}{c}5 \\
(23,8 \%)\end{array}$ & $\begin{array}{c}6 \\
(28,6 \%)\end{array}$ & $\begin{array}{c}3 \\
(14,3 \%)\end{array}$ & $\begin{array}{c}5 \\
(23,8 \%)\end{array}$ & $\begin{array}{c}2 \\
(9,5 \%)\end{array}$ \\
\hline
\end{tabular}

8 - Olhando para as 7 questões, quanto você diria que seu bemestar físico interferiu em sua QV

De 0 a 10

Apesar de aproximadamente metade dos participantes deste estudo não apresentarem enjoo e não sentirem-se doentes, um terço deles sentiam-se com pouca energia, necessitavam deitar-se durante o dia e sentiam dores, como também metade não consegue ou tem dificuldades em atender as necessidades de sua família, pela sua condição física atual.

No pós-transplante o indivíduo antes economicamente ativo com a sua família constituída sofre com o impacto do tratamento e se depara com a mudança de papéis, alterações físicas e fisiológicas que interferem no seu bem-estar e na capacidade de desempenho, principalmente junto a sua família ${ }^{4}$. O sistema de valores do sobrevivente, familiares e sociedade em que está inserido, tem a mesma importância que tinha, mas não a mesma correspondência, todo esse processo de reinserção profissional/social geralmente transcorre e se adapta conforme o tempo passa ${ }^{12}$.

Neste estudo, metade dos participantes tinha como diagnóstico MM, doença que pelo seu comportamento pode causar dor óssea, assim, podemos associar que a dor remanescente no pós TMO pode relacionar-se às consequências da patologia previamente ao transplante, já que a maioria dos participantes tem como patologia este tipo de mieloma. As dores ósseas prejudicam o desempenho cotidiano e a QV, sendo que no mieloma, a dor pode ser descrita como intolerável, podendo ser refratária a analgesia ${ }^{13}$. Na pesquisa de Santos et al. ${ }^{14} \mathrm{com}$ indivíduos pós-TCTH autólogo, quando questionados sobre a dor no pré e pós-transplante, onze dos doze entrevistados apresentavam dor no pré, já no pós, 5 ainda referiram sentir dor. No presente estudo, 8 dos 21 indivíduos referem sentir dor, sendo que $5(23,8 \%)$ deles a descrevem como "muito" presente.

Apesar da dor ainda estar presente, a maioria dos indivíduos relata não sentir-se mais doente, e também que os efeitos colaterais Ihes incomoda parcialmente. No estudo de Dóro et al. ${ }^{15}$ verificou-se que $53,7 \%$ dos sobreviventes consideravam ter uma QV global muito boa, mesmo na presença de sequelas do TCTH.

$\mathrm{Na}$ questão de avaliação final deste domínio, quando questionados "quanto você diria que seu bem-estar físico interferiu em sua QV", em uma avaliação que vai de 0 a 10, a média foi de 6,55. 


\section{Bem-estar social/familiar}

No que diz respeito ao bem-estar social e familiar (Tabela 2), se observa que este parâmetro foi preservado na vida dos entrevistados, sendo que a maioria afirmou ter recebido "muito" apoio de familiares e amigos.

Tabela 2 - Avaliação das questões referentes ao bem-estar social e familiar

\begin{tabular}{|c|c|c|c|c|c|}
\hline $\begin{array}{c}\text { BEM-ESTAR } \\
\text { SOCIAL / FAMILIAR } \\
(n=21)\end{array}$ & $\begin{array}{l}\text { Nem um } \\
\text { pouco }\end{array}$ & Um pouco & $\begin{array}{l}\text { Mais ou } \\
\text { menos }\end{array}$ & Bastante & Muito \\
\hline $\begin{array}{l}9 \text { - Sinto que tenho um } \\
\text { relacionamento distante } \\
\text { com os meus amigos }\end{array}$ & $\begin{array}{c}11 \\
(52,2 \%)\end{array}$ & $\begin{array}{c}1 \\
(4,8 \%)\end{array}$ & $\begin{array}{c}1 \\
(4,8 \%)\end{array}$ & $\begin{array}{c}7 \\
(33,4 \%)\end{array}$ & $\begin{array}{c}1 \\
(4,8 \%)\end{array}$ \\
\hline $\begin{array}{c}10 \text { - Recebo apoio emocional } \\
\text { da minha família }\end{array}$ & $\begin{array}{c}1 \\
(4,8 \%) \\
\end{array}$ & $\begin{array}{c}0 \\
(0,0)\end{array}$ & $\begin{array}{c}2 \\
(9,5 \%) \\
\end{array}$ & $\begin{array}{c}1 \\
(4,8 \%) \\
\end{array}$ & $\begin{array}{c}17 \\
(80,9 \%) \\
\end{array}$ \\
\hline $\begin{array}{l}\text { 11- Recebo apoio } \\
\text { dos meus amigos }\end{array}$ & $\begin{array}{c}0 \\
(0,0 \%)\end{array}$ & $\begin{array}{c}1 \\
(4,8 \%)\end{array}$ & $\begin{array}{c}1 \\
(4,8 \%)\end{array}$ & $\begin{array}{c}4 \\
(19,0 \%)\end{array}$ & $\begin{array}{c}15 \\
(71,4 \%)\end{array}$ \\
\hline $\begin{array}{l}12 \text { - A minha família aceita } \\
\text { a minha doença }\end{array}$ & $\begin{array}{c}0 \\
(0,0 \%) \\
\end{array}$ & $\begin{array}{c}1 \\
(4,8 \%)\end{array}$ & $\begin{array}{c}2 \\
(9,5 \%) \\
\end{array}$ & $\begin{array}{c}1 \\
(4,8 \%) \\
\end{array}$ & $\begin{array}{c}17 \\
(80,9 \%) \\
\end{array}$ \\
\hline $\begin{array}{l}13 \text { - Estou insatisfeito(a) com } \\
\text { a comunicação da família } \\
\text { sobre a minha doença }\end{array}$ & $\begin{array}{c}8 \\
(38,1 \%)\end{array}$ & $\begin{array}{c}1 \\
(4,8 \%)\end{array}$ & $\begin{array}{c}4 \\
(19,0 \%)\end{array}$ & $\begin{array}{c}0 \\
(0,0 \%)\end{array}$ & $\begin{array}{c}8 \\
(38,1 \%)\end{array}$ \\
\hline $\begin{array}{c}14 \text { - Sinto-me próximo(a) do(a) } \\
\text { meu(minha) parceiro(a) (ou } \\
\text { pessoa que me dá } \\
\text { maior apoio) }\end{array}$ & $\begin{array}{c}1 \\
(4,8 \%)\end{array}$ & $\begin{array}{c}0 \\
(0,0 \%)\end{array}$ & $\begin{array}{c}2 \\
(9,5 \%)\end{array}$ & $\begin{array}{c}4 \\
(19,0 \%)\end{array}$ & $\begin{array}{c}14 \\
(66,7 \%)\end{array}$ \\
\hline $\begin{array}{c}15 \text { - Você teve relação sexual } \\
\text { durante o ano passado? NÃO } \\
\text { SIM Se SIM: Eu estou satisfeito } \\
\text { com minha vida sexual }\end{array}$ & $\begin{array}{c}4 \\
(26,7 \%)\end{array}$ & $\begin{array}{c}1 \\
(6,7 \%)\end{array}$ & $\begin{array}{c}2 \\
(13,3 \%)\end{array}$ & $\begin{array}{c}3 \\
(20,0 \%)\end{array}$ & $\begin{array}{c}5 \\
(33,3 \%)\end{array}$ \\
\hline $\begin{array}{l}16 \text { - Olhando para as } 7 \\
\text { questões, quanto você diria } \\
\text { que sua vida social/familiar } \\
\text { interferiu em sua QV }\end{array}$ & \multicolumn{5}{|c|}{ De 0 a 10} \\
\hline
\end{tabular}

Apesar de o transplante ser um processo que necessita de um distanciamento social e limitações sobre o contato com a família, principalmente durante o período de internação e no pós-TCTH imediato, constata-se que a família e amigos, mesmo após todo esse processo, continuam presentes e apoiando a maioria dos participantes deste estudo. Constatando-se a importância da rede social para o bem-estar emocional dos indivíduos com câncer.

Com as mudanças que a doença causa na vida do indivíduo, especificamente no contexto social e familiar, o apoio família/amigos é fundamental na aceitação da enfermidade e para o processo do TCTH ${ }^{16}$. A equipe de saúde multidisciplinar reconhece o forte potencial que a família exerce sobre o paciente, a qual pode ser positiva ou negativa, interferindo diretamente em questões psicoemocionais e sociais do indivíduo, e consequentemente a eficácia do combate à doença e $\mathrm{a} \mathrm{QV}$ dos transplantados 6 .

De acordo com os dados mostrados na Tabela 2, podemos afirmar que a família apresentou um efeito sinérgico positivo frente aos indivíduos do presente trabalho. $\mathrm{Na}$ avaliação geral do domínio bem-estar social/familiar na QV, a média de 8,14 corrobora com esta afirmação. 


\section{Relacionamento com o médico}

Tabela 3 - Avaliação das questões referentes ao Relacionamento com o médico

\begin{tabular}{|c|c|c|c|c|c|}
\hline $\begin{array}{c}\text { RELACIONAMENTO } \\
\text { COM O MÉDICO } \\
(\mathbf{n}=\mathbf{2 1})\end{array}$ & $\begin{array}{l}\text { Nem um } \\
\text { pouco }\end{array}$ & $\begin{array}{l}\text { Um } \\
\text { pouco }\end{array}$ & $\begin{array}{l}\text { Mais ou } \\
\text { menos }\end{array}$ & Bastante & Muito \\
\hline $\begin{array}{c}17 \text { - Tenho confiança no(s) } \\
\text { meu(s) médico(s) }\end{array}$ & $0(0,0 \%)$ & $0(0,0 \%)$ & $\begin{array}{c}1 \\
(4,8 \%)\end{array}$ & $\begin{array}{c}2 \\
(9,5 \%)\end{array}$ & $\begin{array}{c}18 \\
(85,7 \%)\end{array}$ \\
\hline $\begin{array}{l}18 \text { - Meu(s) médico(s) é(são) capaz de } \\
\text { responder minhas questões }\end{array}$ & $0(0,0 \%)$ & $0(0,0 \%)$ & $0(0,0 \%)$ & $\begin{array}{c}7 \\
(33,3 \%)\end{array}$ & $\begin{array}{c}14 \\
(66,7 \%)\end{array}$ \\
\hline $\begin{array}{l}19 \text { - Olhando para as } 2 \text { questões, } \\
\text { quanto você diria que seu } \\
\text { relacionamento com o médico } \\
\text { interferiu em sua QV }\end{array}$ & & & De 0 a 10 & & \\
\hline
\end{tabular}

Pode-se verificar na Tabela 3 que os dois itens que compõem o domínio referente ao relacionamento com 0 médico foram satisfatórios: $85,7 \%$ dos entrevistados têm "muita" confiança nos seus médicos e $66,7 \%$ estão "muito" satisfeitos com os esclarecimentos obtidos.

Munhoz et al. ${ }^{19}$ demonstram que para existir uma relação de confiança médico/paciente, os elementos mais importantes na percepção dos pacientes são: a disponibilidade do médico para falar sobre a doença/responder suas dúvidas e uma linguagem acessível/compreensível. Como profissional da equipe de saúde, observa-se que o atendimento está transmitindo confiança aos indivíduos, como Silva et al. ${ }^{20}$ concluíram em seu estudo que o processo de comunicação entre médico/paciente tem relação direta frente a sensibilidade e sofrimento do indivíduo, como também sobre sua integridade física, psíquica e social, e não somente biológica, possibilitando que a relação seja centrada no paciente e não apenas na doença, configurando um atendimento holístico.

Observou-se na realização desse estudo que a confiança na equipe médica é fundamental desde a decisão para o TMO, como durante o pós-transplante. Ter um bom relacionamento médico/paciente possibilita que as orientações e cuidados necessários sejam aceitos e realizados pelos transplantados e família. Além da confiança, o diálogo efetivo aumenta a confiança do indivíduo sobre o seu tratamento, interferindo positivamente na QV. Confirmado pela média de importância deste domínio sobre a QV, de 9,38.

\section{Bem-estar emocional}

Em relação ao bem-estar emocional (Tabela 4), nota-se que a resposta prevalente foi "nem um pouco". Visto que as perguntas são negativas, a maioria dos pacientes mostrou ter seu bem-estar emocional preservado.

Tabela 4 - Avaliação das questões referentes ao Bem- estar Emocional

\begin{tabular}{|c|c|c|c|c|c|}
\hline $\begin{array}{l}\text { BEM-ESTAR EMOCIONAL } \\
\qquad(n=21)\end{array}$ & $\begin{array}{l}\text { Nem um } \\
\text { pouco }\end{array}$ & Um pouco & $\begin{array}{l}\text { Mais ou } \\
\text { menos }\end{array}$ & Bastante & Muito \\
\hline 20 - Sinto-me triste & $\begin{array}{c}10 \\
(47,7 \%)\end{array}$ & $\begin{array}{c}2 \\
(9,5 \%)\end{array}$ & $4(19,0 \%)$ & $\begin{array}{c}1 \\
(4,8 \%)\end{array}$ & $4(19,0 \%)$ \\
\hline $\begin{array}{l}21 \text { - Estou satisfeito(a) com a } \\
\text { maneira com que enfrento } \\
\text { a minha doença }\end{array}$ & $\begin{array}{c}1 \\
(4,8 \%)\end{array}$ & $\begin{array}{c}1 \\
(4,8 \%)\end{array}$ & $4(19,0 \%)$ & $\begin{array}{c}8 \\
(38,1 \%)\end{array}$ & $7(33,3 \%)$ \\
\hline $\begin{array}{l}22 \text { - Estou perdendo } \\
\text { a esperança na luta } \\
\text { contra minha doença }\end{array}$ & $14(66,7 \%)$ & $\begin{array}{c}3 \\
(14,3 \%)\end{array}$ & $\begin{array}{c}0 \\
(0,0 \%)\end{array}$ & $\begin{array}{c}2 \\
(9,5 \%)\end{array}$ & $\begin{array}{c}2 \\
(9,5 \%)\end{array}$ \\
\hline
\end{tabular}

Continua... 


\begin{tabular}{c|c|c|c|c|c}
\hline $\begin{array}{c}\text { BEM-ESTAR EMOCIONAL } \\
(\mathbf{n = 2 1 )}\end{array}$ & $\begin{array}{c}\text { Nem um } \\
\text { pouco }\end{array}$ & Um pouco & $\begin{array}{c}\text { Mais ou } \\
\text { menos }\end{array}$ & Bastante & Muito \\
\hline 23 - Sinto-me nervoso & $\begin{array}{c}8 \\
(38,1 \%)\end{array}$ & $\begin{array}{c}1 \\
(4,8 \%)\end{array}$ & $\begin{array}{c}8 \\
(38,1 \%)\end{array}$ & $\begin{array}{c}1 \\
(4,8 \%)\end{array}$ & $3(14,2 \%)$ \\
\hline $\begin{array}{c}24 \text { - Estou preocupado(a) com } \\
\text { a ideia de morrer }\end{array}$ & $\begin{array}{c}12 \\
(63,1 \%)\end{array}$ & $\begin{array}{c}3 \\
(15,8 \%)\end{array}$ & $\begin{array}{c}1 \\
(5,3 \%)\end{array}$ & $\begin{array}{c}2 \\
(10,5 \%)\end{array}$ & $\begin{array}{c}1 \\
(5,3 \%)\end{array}$ \\
\hline $\begin{array}{c}25 \text { - Estou preocupado(a) } \\
\text { que a minha condição } \\
\text { venha a piorar }\end{array}$ & $\begin{array}{c}8 \\
(40,0 \%)\end{array}$ & $\begin{array}{c}2 \\
(10,0 \%)\end{array}$ & $\begin{array}{c}6 \\
(30,0 \%)\end{array}$ & $\begin{array}{c}(10,0 \%) \\
2(10,0 \%)\end{array}$ \\
\hline
\end{tabular}

26 - Olhando para as 6 questões, quanto você diria que seu bem-estar emocional De 0 a 10 interferiu em sua QV

Na pesquisa de Proença et al. ${ }^{6}$, que analisou o domínio emocional nas três etapas do TCTH através dos questionários QLQ-C30 e FACT-BMT, os resultados não apresentaram diferenças significativas neste domínio no processo do transplante. Segundo esse autor, entre as possíveis razões deste resultado está o fato dos pacientes terem tido acompanhantes, suporte psicológico durante a terapia, equipe treinada para o acolhimento, e, o principal, o TCTH ser uma possibilidade de cura/remissão da doença.

Apesar de muitos aspectos deste domínio serem favoráveis, como a maioria estar satisfeitos com a maneira que enfrentam a doença, não estar preocupado com a ideia de morrer e não sentirem-se tristes, negativamente aproximadamente metade dos pacientes se encontravam na faixa de mais ou menos /muito nervosos, processo que faz parte da vida de indivíduos que têm o diagnóstico de câncer.

No estudo de Dóro et al. ${ }^{12}$ foi evidenciado que o bem-estar emocional constitui um importante fator de proteção para a preservação da QV, independente do indivíduo ser transplantado ou da população em geral.

A média geral encontrada no domínio avaliado foi de 7,06, logo as questões referentes ao bem estar emocional interfere positivamente na QV dos pacientes.

\section{Bem-estar funcional}

Os resultados referentes ao bem-estar funcional (Tabela 5) apresentaram uma distribuição homogênea, isto é, as respostas foram distribuídas equitativamente entre as opções da escala.

Sobre a capacidade de trabalhar (inclusive em casa), 76,2\% de indivíduos não se sentem aptos a realizar suas atividades "nenhum pouco" (14,3\%), "um pouco" (33,3\%) e "mais ou menos" (28,6\%). Apesar destes dados, mais de $50 \%$ indica que se sente realizado(a) com as atividades que ainda conseguem desempenhar.

Tabela 5 - Avaliação das questões referentes ao bem- estar Funcional

\begin{tabular}{c|c|c|c|c|c}
\hline $\begin{array}{c}\text { BEM-ESTAR FUNCIONAL } \\
\text { (n=21) }\end{array}$ & $\begin{array}{c}\text { Nem um } \\
\text { pouco }\end{array}$ & Um pouco & $\begin{array}{c}\text { Mais ou } \\
\text { menos }\end{array}$ & Bastante & Muito \\
\hline $\begin{array}{c}27 \text { - Sou capaz de trabalhar } \\
\text { (inclusive em casa) }\end{array}$ & $\begin{array}{c}3 \\
(14,3 \%)\end{array}$ & $\begin{array}{c}7 \\
(33,3 \%)\end{array}$ & $\begin{array}{c}6 \\
(28,6 \%)\end{array}$ & $\begin{array}{c}0 \\
(0,0 \%)\end{array}$ & $5(23,8 \%)$ \\
\hline $\begin{array}{c}28 \text { - Sinto-me realizado(a) } \\
\text { com meu trabalho (inclusive } \\
\text { em casa) }\end{array}$ & 1 & $\begin{array}{c}3 \\
(5,0 \%)\end{array}$ & $\begin{array}{c}2 \\
(15,0 \%)\end{array}$ & $\begin{array}{c}(10,0 \%) \\
(45,0 \%)\end{array}$ & $5(25,0 \%)$ \\
\hline $\begin{array}{c}29-\text { Sou capaz de sentir } \\
\text { prazer em viver }\end{array}$ & $\begin{array}{c}0 \\
(0,0 \%)\end{array}$ & $\begin{array}{c}(0,0 \%) \\
(15,0 \%)\end{array}$ & $\begin{array}{c}10 \\
(50,0 \%)\end{array}$ & $7(35,0 \%)$ \\
\hline
\end{tabular}

Continua.. 


\begin{tabular}{c|c|c|c|c|c}
\hline $\begin{array}{c}\text { BEM-ESTAR FUNCIONAL } \\
\text { (n=21) }\end{array}$ & $\begin{array}{c}\text { Nem um } \\
\text { pouco }\end{array}$ & Um pouco & $\begin{array}{c}\text { Mais ou } \\
\text { menos }\end{array}$ & Bastante & Muito \\
\hline 30 - Aceito minha doença & $\begin{array}{c}0 \\
(0,0 \%)\end{array}$ & $\begin{array}{c}1 \\
(5,0 \%)\end{array}$ & $\begin{array}{c}5 \\
(25,0 \%)\end{array}$ & $\begin{array}{c}7 \\
(35,0 \%)\end{array}$ & $7(35,0 \%)$ \\
\hline 31- Durmo bem & $\begin{array}{c}2 \\
(9,5 \%)\end{array}$ & $\begin{array}{c}3 \\
(14,3 \%)\end{array}$ & $\begin{array}{c}6 \\
(28,6 \%)\end{array}$ & $\begin{array}{c}2 \\
(9,5 \%)\end{array}$ & $\begin{array}{c}8 \\
(38,1 \%)\end{array}$ \\
\hline $\begin{array}{c}32 \text { - Costo das coisas que } \\
\text { normalmente faço para } \\
\text { me divertir }\end{array}$ & $\begin{array}{c}2 \\
(10,0 \%)\end{array}$ & $\begin{array}{c}3 \\
(15,0 \%)\end{array}$ & $\begin{array}{c}2 \\
(10,0 \%)\end{array}$ & $\begin{array}{c}6 \\
(30,0 \%)\end{array}$ & $7(35,0 \%)$ \\
\hline $\begin{array}{c}33 \text { - Estou satisfeito(a) com } \\
\text { a qualidade da minha vida } \\
\text { neste momento }\end{array}$ & $\begin{array}{c}(4,8 \%) \\
(14,3 \%)\end{array}$ & $\begin{array}{c}(19,0 \%) \\
(42,9 \%)\end{array}$ & $4(19,0 \%)$ \\
\hline
\end{tabular}

34- Olhando para as 7 questões, quanto você diria que seu bem-estar funcional interferiu em sua QV

De 0 a 10

O achado sobre a dificuldade do transplantado de atender sua família pela condição física, corrobora com a pesquisa de Alves et al. ${ }^{13}$, na qual os dados obtidos nas fases pós-TCTH evidenciarem uma preservação da maioria dos domínios QV, com exceção dos aspectos físicos, pois as limitações físicas decorrentes da terapêutica dificultavam que esses pacientes realizassem seu trabalho e atividades diárias. Outro fator que pode ser associado é a idade média dos participantes ser maior que 50 anos, pois além dos problemas advindos do TMO, ainda há aqueles provenientes da capacidade funcional reduzir naturalmente com o avanço da idade.

A afirmativa sobre o prazer em viver foi a única questão que não teve nenhuma resposta "nenhum pouco" e "um pouco". Doro et al. ${ }^{12} \mathrm{em}$ seu estudo sobre QV de sobreviventes pós-transplante alogênico, em comparação com um grupo controle, explica a aparente discrepância que ocorre entre alguns fatos reais, as respostas e atitudes tomadas pelos sobreviventes. Eles relatam que os efeitos e sintomas existentes com o passar do tempo perdem a intensidade, e apesar de algumas sequelas e comorbidades, os sobreviventes, em geral, estão muito satisfeitos com sua QV, enquanto o grupo controle é mais intolerante, e por isso demonstra mais queixas e insatisfações no dia a dia.

A satisfação com a QV foi classificada por 42,9\% como "bastante" e 19\% como "muito", sendo a média geral do domínio bem estar funcional na QV de 7,43.

\section{Preocupações adicionais}

Tabela 6 - Avaliação das questões referentes às Preocupações adicionais

\begin{tabular}{c|c|c|c|c|c}
\hline $\begin{array}{c}\text { PREOCUPAÇÕES ADICIONAIS } \\
(\mathbf{n = 2 1 )}\end{array}$ & $\begin{array}{c}\text { Nem um } \\
\text { pouco }\end{array}$ & Um pouco & $\begin{array}{c}\text { Mais ou } \\
\text { menos }\end{array}$ & Bastante & Muito \\
\hline $\begin{array}{c}35 \text { - Tenho pensado em retornar } \\
\text { meu trabalho (incluído } \\
\text { trabalho em casa) }\end{array}$ & $\begin{array}{c}3 \\
(14,3 \%)\end{array}$ & $\begin{array}{c}5 \\
(23,8 \%)\end{array}$ & $\begin{array}{c}6 \\
(28,6 \%)\end{array}$ & $\begin{array}{c}2 \\
(9,5 \%)\end{array}$ & $\begin{array}{c}5 \\
(23,8 \%)\end{array}$ \\
\hline $\begin{array}{c}36 \text { - Sinto-me distante de } \\
\text { outras pessoas }\end{array}$ & $\begin{array}{c}11 \\
(52,4 \%)\end{array}$ & $\begin{array}{c}0 \\
(0,0 \%)\end{array}$ & $\begin{array}{c}7 \\
(33,3 \%)\end{array}$ & $\begin{array}{c}2 \\
(9,5 \%)\end{array}$ & $\begin{array}{c}1 \\
(4,8 \%)\end{array}$ \\
\hline $\begin{array}{c}37 \text { - Tenho medo que o } \\
\text { transplante não irá funcionar }\end{array}$ & $\begin{array}{c}10 \\
(50,0 \%)\end{array}$ & $\begin{array}{c}3 \\
(15,0 \%)\end{array}$ & $\begin{array}{c}1 \\
(5,0 \%)\end{array}$ & $\begin{array}{c}5 \\
(25,0 \%)\end{array}$ & $\begin{array}{c}1 \\
(5,0 \%)\end{array}$ \\
\hline $\begin{array}{c}38-\text { Os efeitos do tratamento são } \\
\text { piores que eu tinha imaginado }\end{array}$ & $\begin{array}{c}8 \\
(38,1 \%)\end{array}$ & $\begin{array}{c}1 \\
(4,8 \%)\end{array}$ & $\begin{array}{c}2 \\
(9,5 \%)\end{array}$ & $\begin{array}{c}5 \\
(23,8 \%)\end{array}$ & $\begin{array}{c}5 \\
(23,8 \%)\end{array}$ \\
\hline
\end{tabular}

Continua... 


\begin{tabular}{c|c|c|c|c|c}
\hline $\begin{array}{c}\text { PREOCUPAÇõES ADICIONAIS } \\
\text { (n=21) }\end{array}$ & $\begin{array}{c}\text { Nem um } \\
\text { pouco }\end{array}$ & Um pouco & $\begin{array}{c}\text { Mais ou } \\
\text { menos }\end{array}$ & Bastante & Muito \\
\hline 39 - Tenho bom apetite & $\begin{array}{c}2 \\
(9,5 \%)\end{array}$ & $\begin{array}{c}2 \\
(9,5 \%)\end{array}$ & $\begin{array}{c}3 \\
(14,3 \%)\end{array}$ & $\begin{array}{c}6 \\
(28,6 \%)\end{array}$ & $\begin{array}{c}8 \\
(38,1 \%)\end{array}$ \\
\hline $\begin{array}{c}40 \text { - Gosto da aparência } \\
\text { do meu corpo }\end{array}$ & $\begin{array}{c}2 \\
(10,0 \%)\end{array}$ & $\begin{array}{c}1 \\
(5,0 \%)\end{array}$ & $\begin{array}{c}11 \\
(55,50 \%)\end{array}$ & $\begin{array}{c}3 \\
(15,0 \%)\end{array}$ & $\begin{array}{c}3 \\
(15,0 \%)\end{array}$ \\
\hline $\begin{array}{c}41 \text { - Sou capaz de fazer as coisas } \\
\text { que estão ao meu redor }\end{array}$ & $\begin{array}{c}0 \\
(0,0 \%)\end{array}$ & $\begin{array}{c}6 \\
(28,6 \%)\end{array}$ & $\begin{array}{c}4 \\
(19,0 \%)\end{array}$ & $\begin{array}{c}5 \\
(23,8 \%)\end{array}$ & $\begin{array}{c}6 \\
(28,6 \%)\end{array}$ \\
\hline $\begin{array}{c}42 \text { - Fico cansado(a) fácil } \\
(23,9 \%)\end{array}$ & $\begin{array}{c}2 \\
(9,5 \%)\end{array}$ & $\begin{array}{c}4 \\
(19,0 \%)\end{array}$ & $\begin{array}{c}8 \\
(38,1 \%)\end{array}$ & $\begin{array}{c}2 \\
(9,5 \%)\end{array}$ \\
\hline $\begin{array}{c}43 \text { - Tenho interesse em ter } \\
\text { relação sexual }\end{array}$ & $\begin{array}{c}4 \\
(22,2 \%)\end{array}$ & $\begin{array}{c}3 \\
(16,7 \%)\end{array}$ & $\begin{array}{c}6 \\
(33,3 \%)\end{array}$ & $\begin{array}{c}3 \\
(16,7 \%)\end{array}$ & $\begin{array}{c}2 \\
(11,1 \%)\end{array}$ \\
\hline 44 - Tenho consciência da minha \\
capacidade de ter filhos & $\begin{array}{c}4 \\
(26,7 \%)\end{array}$ & $\begin{array}{c}1 \\
(6,7 \%)\end{array}$ & $\begin{array}{c}4 \\
(26,7 \%)\end{array}$ & $\begin{array}{c}1 \\
(6,7 \%)\end{array}$ & $\begin{array}{c}5 \\
(33,2 \%)\end{array}$ \\
\hline $\begin{array}{c}45 \text { - Tenho confiança em } \\
\text { minha(s) enfermeira(s) }\end{array}$ & $\begin{array}{c}0 \\
(0,0 \%)\end{array}$ & $\begin{array}{c}0 \\
(0,0 \%)\end{array}$ & $\begin{array}{c}1 \\
(4,8 \%)\end{array}$ & $\begin{array}{c}3 \\
(14,3 \%)\end{array}$ & $\begin{array}{c}17 \\
(80,9 \%)\end{array}$ \\
\hline 46 - Regredi fazendo transplante \\
de medula óssea & $\begin{array}{c}11 \\
(52,4 \%)\end{array}$ & $\begin{array}{c}1 \\
(4,8 \%)\end{array}$ & $\begin{array}{c}2 \\
(9,5 \%)\end{array}$ & $\begin{array}{c}3 \\
(14,3 \%)\end{array}$ & $\begin{array}{c}4 \\
(19,0 \%)\end{array}$ \\
\hline
\end{tabular}

47 - Olhando para as doze questões quanto você diria que essas preocupações adicionais De 0 a 10 interferiram na sua QV

Na Tabela 6 foram colocados itens referidos genericamente como "preocupações adicionais". A maioria possui confiança no trabalho das profissionais enfermeiras (80,9\%). Para Castro et al. ${ }^{15} 0$ acompanhamento através da consulta de enfermagem após o transplante torna-se fundamental, auxiliando na redução da dependência dos cuidados institucionalizados, buscando autonomia e corresponsabilização do sujeito em seu tratamento.

Metade dos pacientes não se sentiu em regressão por ter realizado o TCTH $(52,4 \%)$. Na afirmativa que traz sobre o medo de que o transplante não irá funcionar, metade (50\%) mostra não ter "nenhum pouco", sendo que o restante se distribui entre as outras opções. No estudo de Santos et al. ${ }^{14}$ os pacientes sentem prazer na vida mesmo após 0 diagnóstico de câncer e com a doença ativa, antes de realizar o TCTH autólogo. Ainda, um dos pacientes entrevistados "sentia de forma moderada" prazer em viver, e 11 sentiam "muito" prazer em viver, sendo que os resultados permaneceram os mesmos após o tratamento" ${ }^{14}$.

A média de avaliação geral do item referente a preocupações adicionais foi 5,69, e nenhum dos pacientes citou que esses itens interferem muito na sua QV.

Concluindo sobre os achados neste estudo, a maioria dos domínios apresenta-se preservado, sendo o bemestar funcional o que se mostra mais comprometido, ratificado pela pesquisa de Alves et al. ${ }^{16}$ na qual através da FACTBMT confirmou-se a preservação do bom relacionamento com o médico, bem-estar emocional, social e familiar. Em contraponto, 0 aspecto com menor preservação foi o bem-estar funcional, corroborando com o encontrado neste estudo.

Constatamos que a avaliação do indivíduo adoecido, sobre sua QV é singular, pois cada paciente tem percepções diferentes conforme seus valores, patologia, tempo de diagnóstico e expectativa de vida, portanto identificar os domínios afetados no pós TCTH constitui dado importante, visto que essas alterações refletem diretamente na sua QV. 


\section{Considerações Finais}

Os resultados apresentados neste estudo nos permitiram visualizar o impacto positivo do TCTH em relação à QV geral dos pacientes submetidos a este tratamento, apesar de algumas funções apresentarem-se mais comprometidas. Estudos dessa natureza, que identificam a influência dos efeitos do TCTH na QV dos pacientes submetidos a esse procedimento são escassos.

Conhecer o impacto do TCTH na vida do transplantado auxilia a equipe multidisciplinar a desenvolver um plano de assistência integral com estratégias para diminuir os efeitos colaterais desse procedimento e melhorar a qualidade de vida do paciente em todos os momentos do tratamento. Além disso, também pode auxiliar o paciente na decisão de submeter-se a esse procedimento de alta complexidade.

\section{Referências}

1. Lima K, Bernardino E. O cuidado de enfermagem em unidade Transplante de células-tronco hematopoiéticas. Texto \& Contexto Enfermagem. 2014;23(4): 845-53.

2. Instituto Nacional de Câncer José Alencar Gomes da Silva. Tópicos em transplante de células-tronco hematopoiéticas/ Instituto Nacional de Câncer José Alencar Gomes da Silva - Rio de Janeiro: INCA, 2012.

3. Campos P, Martins FG. Paciente em processo pré ou pós transplante de medula óssea (TMO): aspectos emocionais do cuidador familiar. Universidade Presbiteriana Mackenzie, 2011.

4. Proença SFFS. Qualidade de vida nos 100 dias do transplante de células tronco hematopoiéticas. Dissertação (Mestrado), Universidade do Paraná, 2015.

5. Cardoso EAO, Mastropietro AP, Voltarelli JC, Santos MA. Qualidade de Vida de Sobreviventes do Transplante de Medula Óssea (TMO): Um Estudo Prospectivo. Psic.: Teor. e Pesq. 2009; 25(4): $621-8$.

6. Associação brasileira de transplante de órgãos (ABTO). Registro Brasileiro de Transplantes. Dados numéricos da doação de órgãos e transplantes realizados por e instituição no período janeiro-junho (2016): versão internet. 2016. São Paulo, v. XXII, n. 2.

7. The WHOQOL Group. The World Health Organization Quality of Life assessment (WHOQOL): position paper from the World Health Organization. Soc Sci Med. 1995;41(10):1403-9.

8. Zandonai AP, Cardozo FMC, Nieto ING, Sawada NO. Qualidade de vida nos pacientes oncológicos: revisão integrativa da literatura latino-americana. Rev. Eletr. Enf.. 2010;12(3):554-61.

9. Matias AB, Cardoso EAO, Mastropietro AP, Voltarelli JC, Santos MA. Qualidade de vida e transplante de células-tronco hematopoéticas alogênico: um estudo longitudinal. Estud. Psicol. 2011;28(2): 187-7.

10. Mastropietro AP, Oliveira EA, Santos MA, Voltarelli JC. Functional Assessment of Cancer Therapy Bone Marrow Transplantation: tradução e validação. Rev. Saúde Pública. 2007; 41(2) 260-8.

11. Formiga NS. Fidedignidade da escala de condutas anti-sociais e delitivas ao contexto brasileiro. Psicol. Estud.. 2003; $8(2) 133-8$.

12. Dóro MP. Satisfação com a qualidade de vida dos sobreviventes adultos de longa data de pos-transplante de medula óssea alogênico em comparação com um grupo controle. (Tese), Curitiba, 2008.

13. Fialho LFG, Fuly PSC, Santos MLSC, Leite JL, Lins SMSB. Validação do diagnóstico dor óssea e suas intervenções de enfermagem no mieloma múltiplo. Cogitare Enferm. 2014: 19(4):755-60.

14. Santos KB, Reis VN, Dutra HS, Gomes GB. Qualidade de vida pós-transplante autólogo de celulas tronco hematopoeticas. Rev.enf-ufff - 2015; 1 (1)113-121.

15. Castro EAB, Andrade AM, Santos KB, Soares TC, Esterci LT. Autocuidado após o transplante de medula óssea autólogo no processo de cuidar pelo enfermeiro. Rev Rene. 2012; 13(5):1152-62.

16. Alves RP, Cardoso EO, Mastropietro AP, Voltarelli JC, Santos MA. Transplante de células-tronco hematopoéticas e qualidade de vida após alta hospitalar. Psic., Saúde \& Doenças. 2012; 13(1) 87-99. 


\section{Marciele Braga dos Santos}

Endereço para correspondência - Rua: Av. Roraima, $n^{\circ} 1000$, Bairro: Camobi, CEP: 97105-900, Santa Maria, RS , Brasil.

E-mail: marcib@hotmail.com.br Lattes: http://lattes.cnpq.br/8052660603813132

Andreza Lima Cardoso - andrezalimacardoso@gmail.com Bruna Schio - brunaschio91@gmail.com

Francine Ziegler Leal - franzieglerleal@gmail.com Jenifer Colombelli Mielke - jenifercmielke@gmail.com Juliana de Oliveira Mozzaquatro - ju.mozza@gmail.com Rosmari Horner - rosmari.ufsm @gmail.com

\section{Enviado em 01 de fevereiro de 2017. Aceito em 04 de abril de 2017.}

